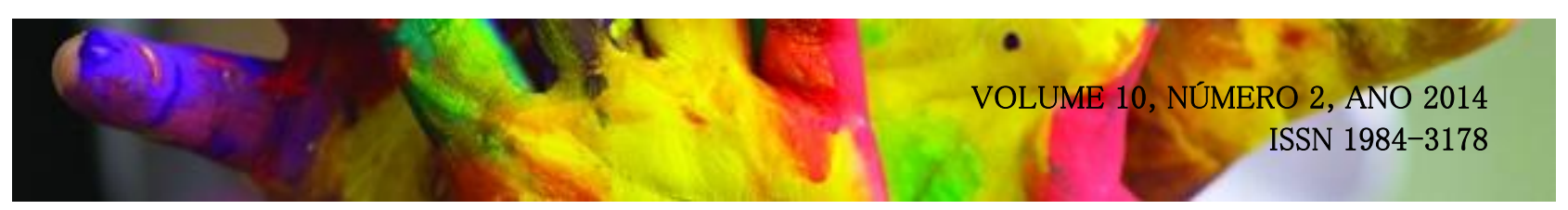

\title{
APRENDIZAGEM MUSICAL E DISTÚRBIO DO PROCESSAMENTO AUDITIVO CENTRAL: RELATO DE UM CASO
}

DOI: http://dx.doi.org/10.5965/198431781022014009

Viviane dos Santos Louro ${ }^{1}$

Gisele Masotti Moraes ${ }^{2}$

Renan Sergio Freitas ${ }^{3}$

\section{RESUMO}

A capacidade do cérebro em interpretar os sons ao nosso redor de forma consciente e funcional denomina-se Processamento Auditivo Central. Pessoas com Distúrbio do Processamento Auditivo (DPAC) podem desenvolver problemas na alfabetização, memória, ou organização em geral, além de sérios problemas na aprendizagem musical. Portanto, o objetivo deste artigo é promover uma reflexão sobre a aprendizagem musical e sua relação com o processamento auditivo relatando o caso de uma aluna com DPAC inclusa em um contexto pedagógico musical de uma tradicional escola de música do Estado de São Paulo. O embasamento teórico foi retirado de artigos científicos publicados nas mais importantes bases de dados, bem como, de livros das áreas de música e processamento auditivo. Para o relato de caso, foram utilizadas as anotações das intervenções pedagógicas do prontuário da aluna de música. As discussões concluem que há uma grande relação entre a dificuldade de aprendizagem musical e o Distúrbio do Processamento Auditivo, como também, a possibilidade de diminuição dessas dificuldades a partir de intervenção terapêutica e pedagógica musical adequada.

Palavras-chaves: Processamento auditivo; DPAC; aprendizagem musical, inclusão, formação de professores;

Doutoranda - Unifesp (Universidade Federal de São Paulo) - Escola Paulista de Medicina. Disciplina de Neurologia Experimental / Departamento de Neurologia e Neurocirurgia. Coordenadora do grupo de estudos Música, Neurociências e Inclusão. Telefone: (11) 5576-4848. Ramal: 2838. . Rua Pedro de Toledo, 669. Vila Mariana, São Paulo - SP, Brasil - CEP: 040.39-032. E-mail: viviane_louro@uol.com.br.

2 Unesp (Universidade Estadual Paulista Julio de Mesquita Filho) - Instituto de Artes. Departamento de música: Licenciatura em Educação Musical. Integrante do grupo de estudos Música, Neurociências e Inclusão. Rua Dr. Bento Teobaldo Ferraz, 271 - Barra Funda, CEP 01140-070, São Paulo - SP. E-mail: gimmoraes@ hotmail.com.

Unimes (Universidade Metropolitana de Santos). Modalidade de Ensino a Distância: Licenciatura em educação musical. Integrante do grupo de estudos Música e inclusão. Avenida Antônio Manuel de Carvalho, N.3.935 Morro da nova Cintra - Santos-SP, Brasil - CEP 11080-300 Telefone (13) 3228-3400. E-mail: Renan.sfreitas@ gmail.com.

Autores integrantes do grupo de estudos GERMINA e o site:Www.neuromusica.wordpress.com 


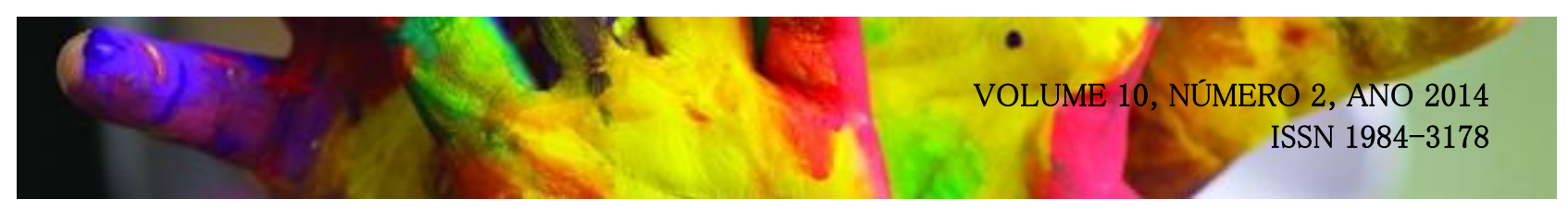

\title{
LEARNING MUSICAL AND CENTRAL AUDITORY PROCESSING DISORDER: A CASE REPORT
}

\begin{abstract}
The ability of the brain to interpret the sounds around us in a consciously and functional form is called Central Auditory Process. People with Central Auditory Processing Disorder (CAPD) may develop problems in literacy, memory, or organization in general, and serious problems in musical learning. Therefore, the aim of this article is to promote reflection on learning music and its relation

to auditory processing and report the case of a student with CAPD included in a musical pedagogical context in a traditional music school in São Paulo state.The theoretical basis was taken from scientific articles published in huge databases, as well as books in the areas of music and hearing process. For the case report, the notes of pedagogical interventions from medical records of a music student in a huge art school in São Paulo State were used. Discussions conclude that there is a great relation between the difficulty of learning music and Auditory Processing Disorder, as well as the possibility of lowering these musical difficulties from an adequate therapeutic and educational intervention.
\end{abstract}

Keywords: hearing process; CAPD; musical learning, inclusion, and teacher training

\section{Palavras introdutórias}

Pesquisas afirmam a importância da música como elemento para ampliação das funções cerebrais e abordam a relação do processamento auditivo para a vida diária e para a aprendizagem em geral (MÜLLER, R. 2013; ROCHA \& BOGGIO, 2013; MUSZKAT, et. al. 2000; NUNES et. al. 2012). Consoante Mendonça e Lemos (2010, p. 64):

\footnotetext{
A prática musical pode ser apontada como uma das formas de se melhorar aspectos da audição e do processamento auditivo e pode ser considerada como um fator de proteção em relação a distúrbios de desenvolvimento, em especial, àqueles relacionados ao desenvolvimento de fala e linguagem. [...] A prática musical possui por si só grande valor cultural e artístico, mas, além disso, oferece suporte para o desenvolvimento de outras habilidades cognitivas, o que agrega ainda mais valor ao seu aprendizado (MENDONÇA \& LEMOS, 2010, p. 65).
}

Os estudos que relacionam processamento auditivo com música, geralmente, possuem como 


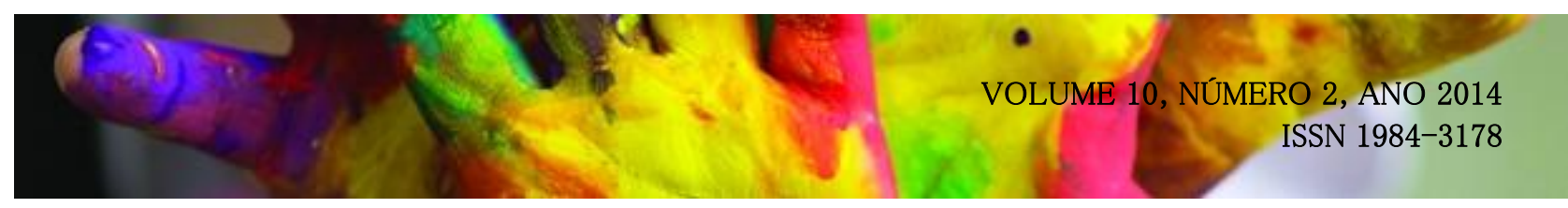

foco observar como a mente percebe, interpreta, apreende e comanda a música, além dos processos anatomofisiológicos envolvidos na percepção, aprendizagem e cognição (CUERVO, 2011). Poucas são as pesquisas que tentam retratar as dificuldades que pessoas com problemas de processamento auditivo podem apresentar na aquisição do conhecimento musical.

Por esse motivo, este artigo tem por objetivo promover uma discussão sobre a relação da aprendizagem musical com o processamento auditivo e a seguir, relatar um caso sobre a inclusão de uma aluna com Distúrbio do Processamento Auditivo Central em uma significativa escola de música do Estado de São Paulo.

O embasamento teórico foi retirado de artigos científicos publicados nas bases de dados da Pubmed, Lilacs, Bireme, Scielo, bem como, das revistas da Associação Brasileira de Educação Musical (ABEM) e de livros das áreas de música e processamento auditivo. Para o relato de caso, foram utilizados os exames de processamento auditivo, bem como, as anotações das entrevistas, reuniões e intervenções pedagógicas do prontuário da aluna em questão.

\section{Sistema auditivo periférico e processamento auditivo central}

Processamento Auditivo (PA) é um conjunto de habilidades específicas das quais o indivíduo depende para compreender o que ouve. É uma atividade mental, isso é, uma função cerebral e, assim sendo, não pode ser estudada como um fenômeno unitário, mas sim, como uma resposta multidimensional aos estímulos recebidos por meio da audição (ALVAREZ et. al., 2007).

Da entrada do som pelo pavilhão auditivo (orelha) até a chegada no nervo auditivo, isto é, todo o percurso que o som faz para chegar até o cérebro é considerado sistema auditivo periférico. Já o processamento auditivo, ou também chamado sistema auditivo central, se destina somente ao processamento da informação no momento em que o estimulo sonoro chega ao córtex auditivo (PAULUCCI, 2005). 


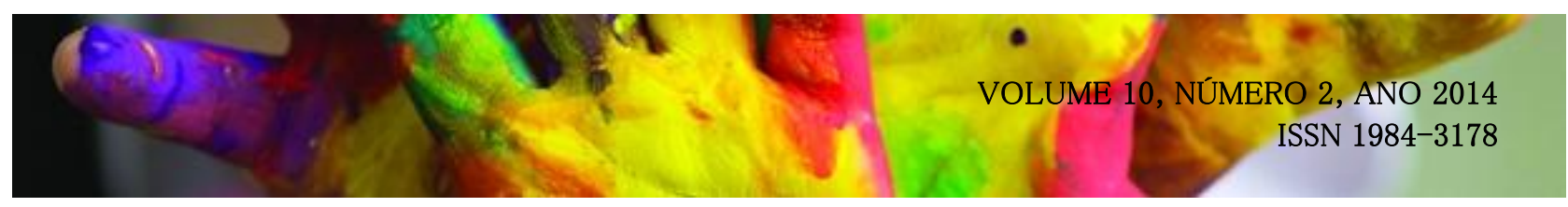

O sistema auditivo periférico (figura 1) é formado pelo ouvido externo, ouvido médio e ouvido interno. O ouvido externo é formado pelo pavilhão auditivo (orelha) - que faz a função de uma caixa acústica - e pelo conduto auditivo - que leva as informações até o tímpano. No ouvido médio, além do tímpano (uma membrana fina e flexível), se encontram os três ossículos: Martelo, Bigorna e Estribo, que potencializam as ondas sonoras e as levam até o ouvido interno, onde encontramos a cóclea, que transforma as ondas sonoras em impulsos elétricos e as envia para o nervo auditivo que, consequentemente, transmite as informações para o córtex analisar. No momento em que essas informações chegam ao cérebro, ocorre o processamento auditivo, ou seja, a recepção, análise e interpretação do som, transformando-o em um pensamento, sentimento, intenção ou ação motora (PAULUCCI, 2005).

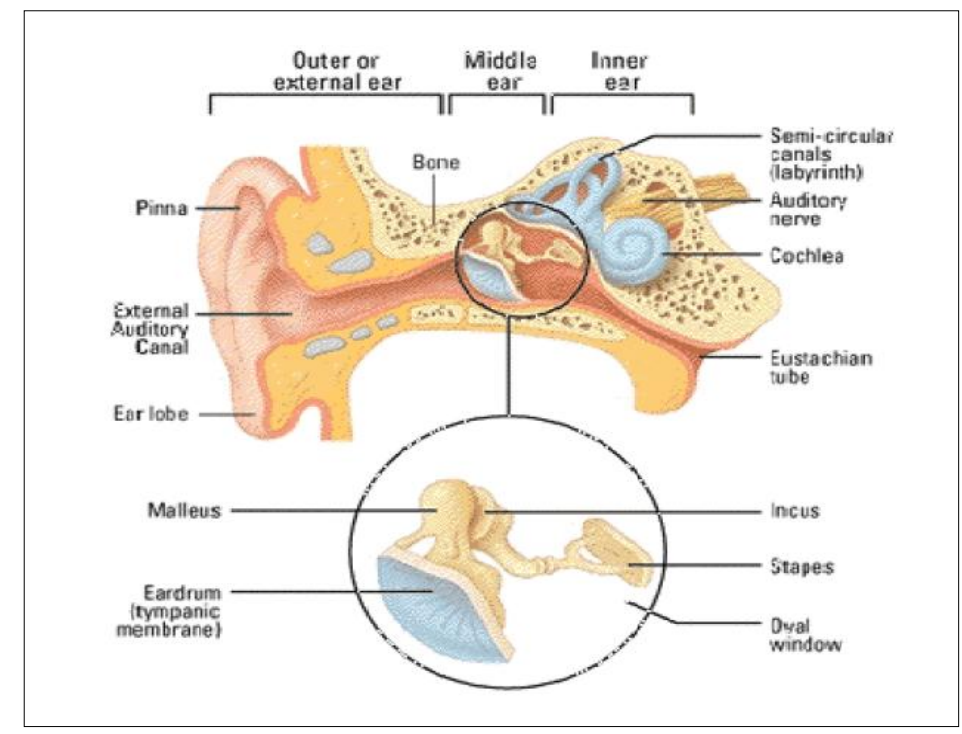

Figura 1. Sistema auditivo periférico. Retirado de Pacheco (2014, p.1).

Portanto, processamento auditivo é diferente de sistema auditivo periférico. Sistema auditivo periférico serve apenas para captação e transporte do som, é como se fosse um microfone, onde recebe as informações e as transmite para a mesa de som. Porém, quem vai interpretar e programar a ação a partir desse estimulo sonoro, é a mesa de som, ou seja, nosso cérebro. 


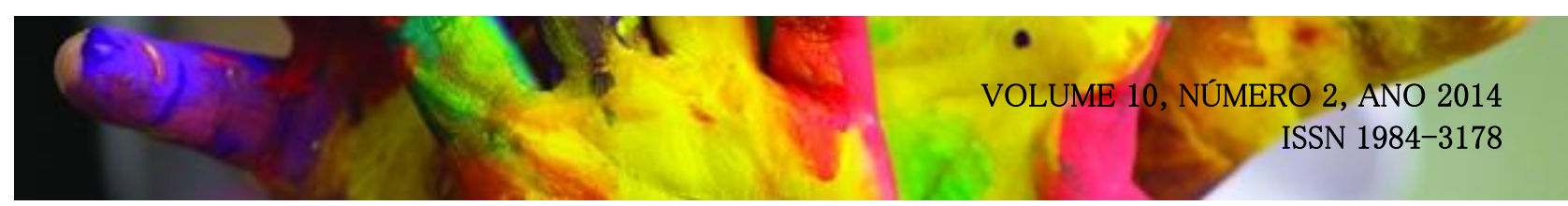

\section{Etapas e habilidades do processamento auditivo}

Quando os impulsos elétricos chegam ao córtex para análise, ele passa por cinco etapas (BOOTHROID, 1986, Apud STEINER, 1999), a saber:

1. Detecção e sensação: que é quando o cérebro descobre se tem som ou silêncio;

2. Discriminação: percepção de padrões de altura (agudo e grave), intensidade (forte e fraco) e duração (sons longos ou curtos);

3. Localização: direção do som (se vem da frente, dos lados, etc);

4. Reconhecimento: percepção do timbre, ou seja, identificação de quem (ou o quê) emitiu o som, se foi um piano, violão, uma mulher falando, etc.

5. Compreensão: interpretação e reação ao som.

Para que haja um processamento auditivo eficiente, nosso cérebro precisa desenvolver algumas habilidades, a saber:

* Atenção seletiva: quando, mesmo com vários estímulos sonoros, nós conseguimos nos focar em apenas um específico ou principal. Por exemplo, quando se está em um lugar público com muitos ruídos e nos concentramos na conversa que estamos tendo ao celular; Isso também podemos chamar de figura-fundo auditivo, ou seja, a capacidade de focarmos num som específico e isolarmos os outros que não são importantes naquele momento (GARCIA, et al., 2007).

* Fechamento auditivo: consiste em "fechar" a informação sonora, quando esta não está completa, ou seja, completar internamente trechos de uma conversa em que ouvimos somente algumas palavras ou conseguir entender determinada frase sem ouvir todas as palavras (JACOB, et al., 2000).

* Habilidade do padrão temporal: Segundo Shinn (2003, p.52) “definida como a percepção do som ou da alteração do som dentro de um domínio de tempo limitado ou definido.” Em outras palavras, é a capacidade de reconhecimento de determinados padrões do som. Shinn (2003, P.52) e Jacob, et al., (2000), define alguns desses padrões: 


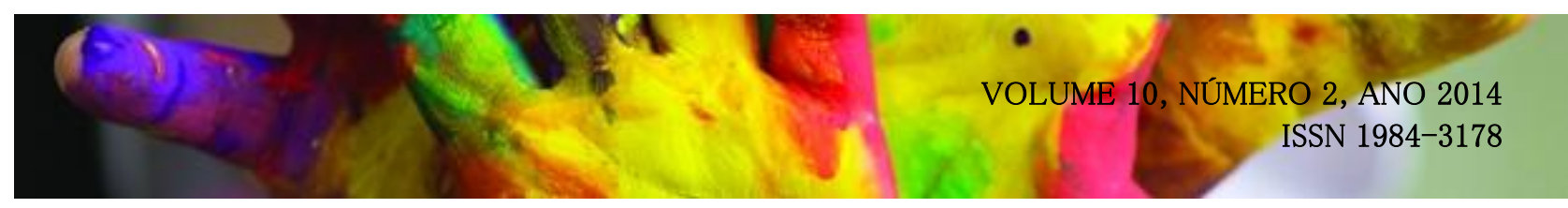

1. Ordenação temporal, ou sequenciamento temporal: capacidade de ordenar o som. Por exemplo: BOA ou OBA. A ordenação das letras muda todo o significado da palavra.

2. Discriminação ou resolução temporal: é o menor tempo em que as pessoas conseguem diferenciar um som do outro. É ouvir o silêncio que há entre os sons.

3. Integração temporal: "habilidade do sistema auditivo em adicionar informação ao longo do tempo para aumentar a detecção ou a discriminação do estímulo" (LIPORACI, 2009)

4. Mascaramento temporal: quando um estímulo sonoro tem a duração e a intensidade forte o suficiente para reduzir a sensibilidade de outra fonte sonora (SAMELLI, et al., 2008).

5. Entonação temporal: perceber a intenção por trás da fala ou, através da voz, reconhecer se a pessoa está brava ou triste, se o que ela fala é uma indagação ou uma afirmação. É o que chamamos de sons suprassegmentais da fala, ou seja, a intenção por trás das palavras.

6.Tonicidade é a capacidade de identificarmos as sílabas "surdas", ou seja, o que nos permite compreender auditivamente a diferença entre as palavras, exemplo: Faca e Vaca.

* Memória auditiva: é o armazenamento e recuperação de determinados sons e a capacidade de os associarmos a lembranças, sentimentos, ações e imagens (JACOB, et al.,2000).

* Integração binaural: capacidade de integrar neurologicamente os sons ouvidos em ambas as orelhas. É quando dois sons que se completam são executados simultaneamente ou sequencialmente em orelhas diferentes, e o cérebro consegue decifrar como uma única mensagem (ALVAREZ et. al., 2007).

Todas essas habilidades são fundamentais para nossa vida cotidiana e acadêmica e apresentar qualquer distúrbio em uma dessas habilidades, pode causar grandes dificuldades no aprendizado.

\section{Distúrbios do Processamento Auditivo Central (DPAC) e tratamentos}




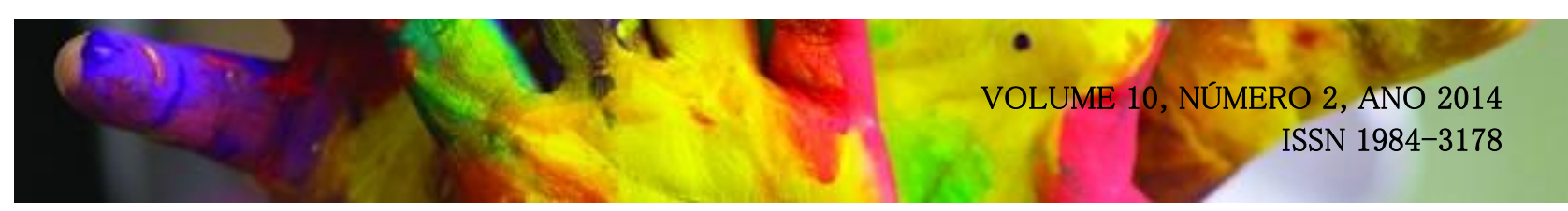

O Distúrbio do Processamento Auditivo Central (DPAC) acontece quando algo afeta, de forma adversa, o processamento da informação auditiva. Esse distúrbio faz com que ocorra uma dificuldade na interpretação dos padrões sonoros e pode, consequentemente, ocasionar prejuízos na compreensão das informações, alterações no comportamento e em decorrência disso, o fracasso escolar (MARTINS, et al. 2008).

É importante ressaltar que há diferença entre deficiência auditiva e DPAC. Quando temos alguma falha no sistema auditivo periférico, ou seja, qualquer problema no ouvido externo, médio ou interno, que faça com que o estímulo sonoro não complete todo o percurso para chegar ao cérebro, temos uma deficiência auditiva. "A deficiência auditiva pode ser classificada de acordo com o grau de perda da audição. Esta perda é avaliada pela intensidade do som, medida em decibéis (dB), em cada um dos ouvidos ( DESSEN \& BRITO, 1997.). Se o estímulo sonoro chega intacto ao cérebro, mas o córtex não consegue interpretar essas informações, então temos um DPAC (ZALCMAN \& SCHOCHAT, 2007).

Para se fazer uma avaliação do sistema auditivo periférico e descobrir algum sintoma de deficiência usa-se a audiometria e a imitanciometria e para uma avaliação no PA realizam-se diversos exames que avaliam todas as habilidades e etapas do PA (Parra et al., 2004). Essas avaliações são compostas por diversos exames que dificultam a audição, fazendo assim uma análise de qual habilidade está comprometida. O fonoaudiólogo responsável pelos testes pode fazer uma análise das escutas monótica, dicótica e diótica ${ }^{4}$ (STEINER, 1999). Este teste tem o nome de Exame de Processamento Auditivo Central.

Existem diversos testes para se descobrir qual ou quais habilidades do processamento foram comprometidas. Dentre as estratégias para se fazer o diagnóstico, temos a anamnese detalhada (uma entrevista de mapeamento das dificuldades); testes não audiológicos (avaliação do desempenho

\footnotetext{
$4 \quad$ Escuta monótica: é quando o fonoaudiólogo faz os testes em cada orelha separadamente, uma de cada vez. Escuta dicótica: é quando o teste se faz nas duas orelhas, porém cada orelha recebe um estímulo sonoro diferente. Escuta diótica: quando o mesmo estímulo sonoro se faz nas duas orelhas ao mesmo tempo. (STEINER, 1999).
} 


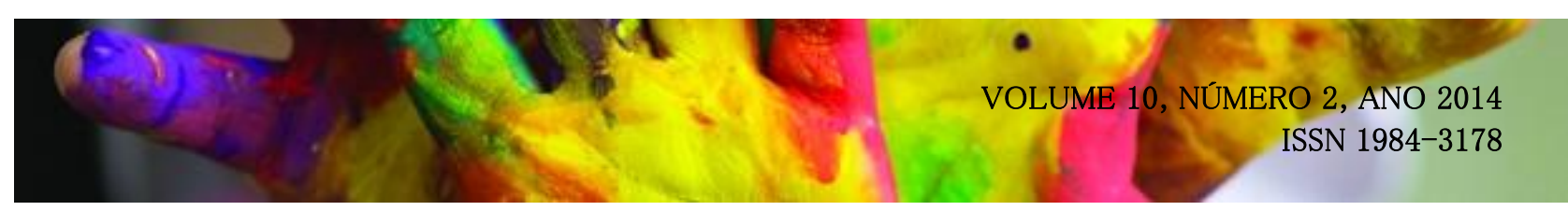

linguístico e comportamento auditivo) e testes audiológicos (que tem enfoque em detectar as questões neurológicas da audição) (BELLIS 2003, apud KOZLOWSKI, 2004).

Quando uma ou mais habilidades do PA está comprometida, sejam elas por causas primárias ou secundárias $^{5}$, podemos enfrentar problemas de aprendizagem. Os mais comuns são: dificuldades em compreender a língua falada, seguir ordens de comandos verbais, se organizar no espaço a partir de comandos verbais, trocas de letras na leitura, fala e escrita, imaturidade na compreensão de piadas ou duplos sentidos, problema com memória e atenção seletiva (RIBAS et al., 2007)

Esses problemas são, por vezes, confundidos com preguiça, falta de estudo ou com outros distúrbios, tais como dislexia ou déficit de atenção. Por isso, é importante uma investigação detalhada por parte de um profissional qualificado, no caso, um fonoaudiólogo, em união com os professores, que geralmente, são os que detectam primeiramente o problema.

Cada caso vai exigir uma determinada ação no tratamento, mas de um modo geral, todos são realizados em cabine com fones de ouvido e direcionado por um fonoaudiólogo. Cada exercício proposto pelo fonoaudiólogo, terá o objetivo de desenvolver uma ou mais habilidades do processamento, tais como, memória auditiva, atenção seletiva com realização de exercícios de figura-fundo auditivo, consciência do planejamento motor a partir da informação acústica ou a consciência fonológica, através da reflexão da estrutura sonora das palavras faladas (KOZLOWSKI, 2004).

\section{Aprendizagem musical e processamento auditivo}

Dentro dos cursos técnicos e superiores, as disciplinas Percepção e Rítmica ${ }^{6}$, fazem parte da vida dos estudantes de música, e são, dentre todas as disciplinas, as mais fáceis de detectar alunos com problemas de processamento auditivo, pois são disciplinas voltadas ao treinamento auditivo para reconhecimento de melodias e ritmos.

Sem um processamento auditivo adequado, ou

5

Causa primária: quando o distúrbio do processamento auditivo é o problema principal ou único. Causa secundária: quando o distúrbio está associado a alguma outra doença ou transtorno, como por exemplo: autismo, dislexia, afasia, esclerose múltipla, etc (KOZLOWSKI, 2004).

6 A disciplina de percepção se destina a treinar a audição para conseguir escrever melodias (as notas musicais que compõe uma melodia) somente ouvindo-as e a disciplina de rítmica se destina a treinar a audição para ouvir padrões de sons que combinados entre si viram os ritmos de uma melodia, bem como, também se destina a compreender os padrões matemáticos das proporções entre as figuras musicais. 


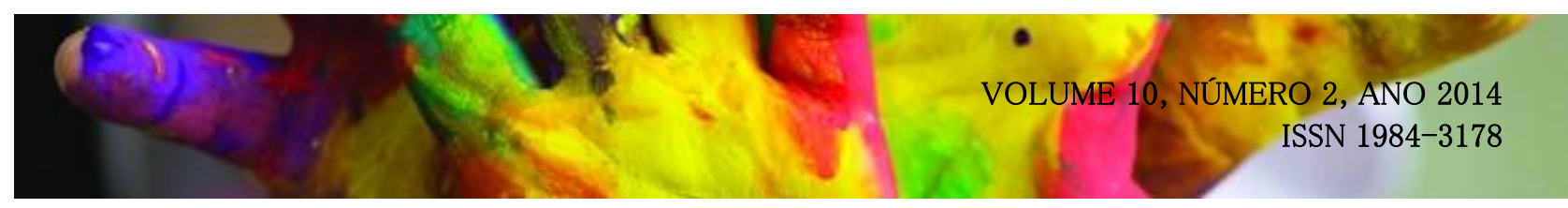

seja, sem a maturação neurológica esperada para a compreensão do fenômeno sonoro, a apreensão musical pode ficar comprometida (MENDONÇA \& LEMOS, 2010).

Conforme Muller (2013, p. 8), os processos perceptivos auditivos se dividem em 4 grandes áreas, sendo elas:

1. Atenção: alertar para a existência do som e o selecionar conforme a necessidade.

2. Discriminação: capacidade do cérebro em distinguir as características elementares do som (duração, altura, timbre, intensidade);

3. Integração: onde se relacionam as informações auditivas a outras modalidades sensoriais, tais como ouvir e escrever (audição-visão-mão);

4. Prosódia: habilidades relacionadas à recepção e à interpretação dos padrões supra-segmentais, não verbais, da mensagem recebida, tais como ritmo, entonação e intenção da fala.

O desenvolvimento da percepção e rítmica passa por pelo menos três dos itens acima citados: atenção, discriminação e integração. Sem atenção, a informação não pode alcançar a cognição e ser interpretada. Discriminar padrões sonoros é a essência da realização de um ditado rítmico ou melódico e sem integrar a informação sonora, fica inviável codificar os sons ouvidos, em símbolos musicais escritos. Estas inabilidades auditivas não dificultam apenas o aprendizado musical, mas também o desenvolvimento da linguagem escrita e falada (FROTA \& PEREIRA, 2010).

A partir dos autores Cioqueta (2006) e Lima (2010) podemos traçar um paralelo mais detalhado entre as habilidades auditivas e a compreensão de quesitos da aprendizagem musical.

Problemas na discriminação do padrão sonoro (reconhecimento de duração, altura e intensidade) contribuem sensivelmente de forma negativa na realização de ditados rítmicos e melódicos musicais, pois estes dependem profundamente da capacidade de nosso cérebro, em reconhecer e comparar os padrões de figuras e alturas, para que depois possam ser organizados sequencialmente na escrita.

Esta habilidade auditiva está também relacionada com a capacidade de interpretação musical, 


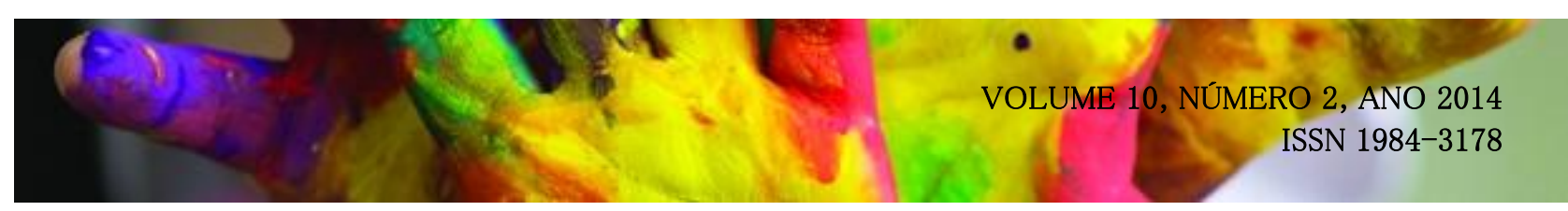

através da diferenciação dos padrões de intensidade ${ }^{7}$. A gradação da intensidade numa frase musical, que oferecerá a ela o diferencial interpretativo dentro de uma obra, depende da compreensão do cérebro em detectar, avaliar e modular motoramente, a partir das Funções Executivas, o que e como deverá ser executado um trecho musical.

Godoy (2010, p. 77) coloca Funções Executivas como a capacidade do sujeito em realizar "ações voluntárias, independentes, autônomas, auto-organizadas e orientadas para metas específicas". Para isso, o indivíduo precisa ter a capacidade de considerar e refletir sobre informações diversificadas, integrando-as. Além disso, precisa ser hábil em alternar o foco atencional entre duas ou mais tarefas, para que possa regular o próprio comportamento e planejar estratégias sequenciais para atingir um objetivo (HUIZINGA, 2007, p. 2018).

Muitas das áreas auditivas são responsáveis pela manutenção da atenção, controle executivo e regulação motora. Vias auditivas presentes no corpo caloso, responsáveis pela transferência interhemisférica desempenham um papel no controle atencional e na sua modulação, além da sua atividade sensorial. Fica clara, assim, a relação estreita entre atenção concentrada auditiva e a habilidade de figura-fundo auditiva com as Funções Executivas (PRANDO, 2010).

Sendo assim, se não há uma audição ativa, que interpreta as informações adequadamente, as respostas motoras e comportamentais podem não ser adequadas. Por exemplo, ao ouvir um barulho que pareça um som de tiro, a pessoa precisa elaborar uma estratégia rápida para fuga ou proteção. Para isso, ela aciona as Funções Executivas. Se não conseguir interpretar o barulho como sendo um tiro, ou seja, se o processamento auditivo no reconhecimento de timbre falha, suas atitudes poderão não ser adequadas à situação (PRANDO, 2010).

Isso pode ser transposto para a aprendizagem musical. Se há uma falha no processamento auditivo em reconhecimento de timbre, por exemplo, as respostas em relação a reconhecimento de sons instrumentais podem ser alteradas, o que pode prejudicar o rendimento de um aluno de música, numa aula de apreciação ${ }^{8}$, ou numa execução instrumental diante de uma orquestra, por exemplo.

\footnotetext{
7 Intensidade, em música, é uma das propriedades do som e se destina à capacidade de reconhecer auditivamente e executar motoramente os sons com maior ou menor volume, isto é, tocar forte ou fraco e todas as gradações entre esses itens.

8 A disciplina de apreciação musical tem por objetivo treinar o ouvido para que ele reconheça os sons dos instrumentos de orquestra.
} 


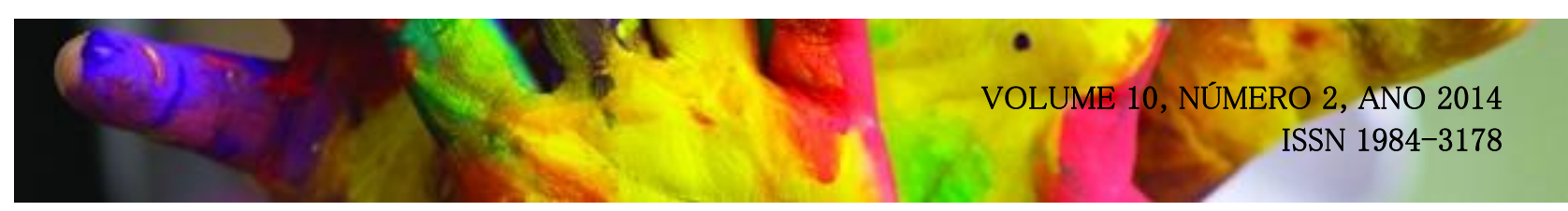

Ou, se o aluno não consegue processar auditivamente padrões como altura e duração, poderá não conseguir ler e cantar ou tocar uma partitura, ou seja, um prejuízo no processamento auditivo pode gerar um prejuízo na execução instrumental a partir de uma interferência nas Funções Executivas.

Outras duas habilidades do processamento são a ordenação e resolução temporal. A habilidade de ordenação temporal refere-se ao processamento de múltiplos estímulos auditivos na sua ordem de ocorrência, podendo assim um indivíduo ser capaz de discriminar a correta ordem de ocorrência dos sons verbais e não verbais (NISHIHATA, 2012). Esta habilidade se relaciona com a capacidade de sequenciar os fenômenos musicais, isto é, colocar as notas ou ritmos na sequência correta, a partir da audição de uma melodia. Se isso está comprometido, possivelmente o aluno não conseguirá ordenar na escrita o que ouve diante de um ditado musical.

Já a resolução temporal, é a capacidade de detectar intervalos de tempo entre estímulos sonoros ou detectar o menor tempo que um indivíduo possa discriminar entre dois sinais audíveis (NISHIHATA, 2012). Na música, é responsável por contribuir na percepção da periodicidade da pulsação. Igualmente importante, é sua participação na percepção de quantidade de ataques sonoros e na diferenciação entre som e silêncio, ou seja, no potencial neurológico de percebermos o silêncio que há entre os sons. Isso é fundamental quando se escreve um ditado de percepção ou rítmica.

Um aluno de música com dificuldade na resolução temporal poderá inverter a sequência de notas e ritmos, não conseguir marcar pulsação, não conseguir ouvir quantidade de ataques por pulsação, o que é fundamental para se escrever um ditado, além de poder apresentar prejuízo na percepção do silêncio entre os sons. Por exemplo, se um professor tocar quatro notas rápidas, na mesma altura, uma pessoa com bom processamento auditivo será capaz de percebê-las. Já uma pessoa com distúrbio na resolução temporal poderá "unir" todas essas notas, por não perceber o silêncio que as separa e acabar ouvindo um som prolongado ao invés de quatro ataques distintos sequencialmente.

A capacidade auditiva de figura-fundo é outro requisito do processamento, ligado à música. Ela nos permite prestar atenção num foco sonoro específico e deixar os sons do ambiente, em segundo plano. Isso é essencial para a escrita musical a partir da audição, primeiramente pelo próprio ambiente em si, isto é, no momento em que se escreve um ditado rítmico ou melódico, é necessário foco auditivo no exercício em questão, deixando de lado ruídos como portas abrindo, passos pelos 


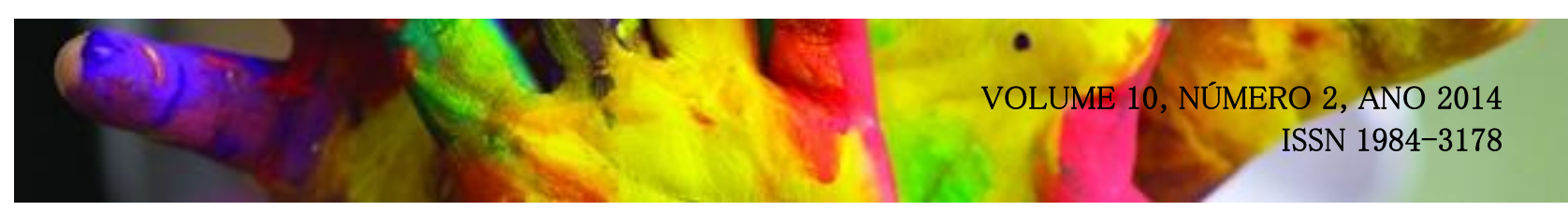

corredores, conversas paralelas, carros passando na rua, dentre outros. Se por exemplo, o professor fizer um ditado rítmico a duas vozes ${ }^{9}$, essa habilidade se torna essencial também, pois a atenção precisa ser alternada, hora para a primeira voz e hora para a segunda, para poder ser retratada em forma de escrita posteriormente (PEREIRA, 2006).

Além disso, quem tem dificuldade com figura - fundo auditivo pode apresentar dificuldades na aula de apreciação. Pois, ouvir um instrumento solista diante de uma orquestra depende de conseguir destacar auditivamente o instrumento mais importante, dos demais e para isso a capacidade de figura-fundo é importante.

Outro item fundamental do processamento auditivo e que se relaciona com toda a aprendizagem musical é a memória auditiva. Quando queremos escrever uma melodia, precisamos ouvi-la diversas vezes para podermos comparar os padrões de duração ${ }^{10}$ e altura $^{11}$, bem como, questões como intervalos, tonalidade e harmonia ${ }^{12}$. Tudo isso integrado nos dá a noção do todo melódico e contribui para a decodificação. Mas, sem memória, nada disso é possível.

Consoante Lent (2010), a memória é um dos mecanismos cognitivos mais importantes, pois é ela que nos permite recuperar dados do passado e projetar informações para o futuro. Mendonça (2010, p. 59) já completa dizendo que "a memória auditiva é a responsável pela aquisição, armazenamento e arquivamento das informações e está intimamente relacionada ao processo de aprendizagem". Sendo assim, é ela que nos permite comparar um som ao outro, ou refazer a melodia mais lenta mentalmente, entre uma audição e outra, do ditado. Portanto, se a memória auditiva falha, o aluno pode não conseguir escrever as melodias rítmicas e melódicas, pois não consegue armazenar a informação. Ou então, pode até recrutar a informação sonora, mas não consegue recuperá-la de forma consciente ou quando a recupera, o faz de forma distorcida, por não ter memorizado direito (MENDONÇA 2010).

Por último, podemos pensar também na questão emocional da música e sua relação com o

\footnotetext{
9 Ou seja, com duas melodias diferentes, ao mesmo tempo.

10 Sons curtos e longos que combinados viram as figuras musicais.

Sons graves, médios e agudos que são nomeadas de acordo com a frequência, são as notas musicais.

Tonalidade é a estrutura de organização dos intervalos entre as notas que oferece à música uma sonoridade específica. Podemos ter tonalidades maiores e menores e cada uma delas terá uma organização diferente entre as notas. Harmonia são os acordes que podemos formar dentro de uma tonalidade e esses acordes possuem funções específicas que fazem com que a música tenha momentos de tensões e relaxamento.
} 


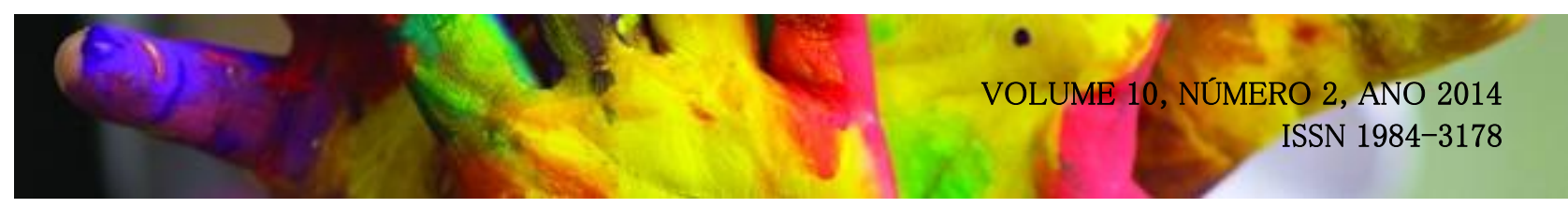

processamento auditivo. Estudos demonstram que a música ativa as mesmas zonas cerebrais que participam do processamento das emoções. Sabe-se, também, que a estimulação auditiva resulta em mudanças morfológicas e funcionais, aprimorando e aperfeiçoando a função auditiva (CIOQUETA, 2006). Sendo assim, uma audição não funcional, pontuada por um distúrbio, pode contribuir para uma emocionalidade não madura e isso pode interferir na aprendizagem e interpretação musical, uma vez que "os fatores emocionais são fundamentais para a existência da música" (SLOBODA, 1985, p. 2).

Em suma, pessoas com distúrbio de processamento auditivo central, podem apresentar severas dificuldades na aquisição musical, principalmente em disciplinas que dependem da acuidade auditiva, como é o caso da percepção, rítmica e apreciação musical. Isso nos deixa um alerta e uma pergunta importante: será que os professores de música tem conhecimento suficiente sobre essas questões? Será que as escolas de música estão preparadas para trabalhar a inclusão de alunos que apresentam DPAC? Essas duas questões serão retomadas na discussão após o relato de caso.

\section{Relato de Caso}

Joana $^{13}, 34$ anos, faz aulas de música numa escola tradicional do Estado de São Paulo, desde o ano de 2009. Essa escola possui cursos livres e profissionalizantes em música, sendo muito significativa na formação de diversos músicos brasileiros renomados. Desde que a aluna adentrou o curso de música, demonstrou dificuldade de aprendizagem. Seu maior obstáculo era em relação à percepção e rítmica ou a qualquer atividade musical que exigisse associação do som com alguma ação motora ou elemento teórico.

Nos exercícios de ditado rítmico e melódico, era comum Joana inverter os padrões sonoros, por exemplo, se o professor tocasse um trecho em grau conjunto ascendente, ela escrevia descendente ${ }^{14}$. Além disso, não percebia distância entre as notas: um grau conjunto virara em seu ditado, um salto

\footnotetext{
13 Nome fictício para preservar a identidade da aluna.

14 Isto é: se o professor fizesse uma nota grave e outra aguda, ela escrevia que primeiramente tinha sido feita a aguda e depois a grave.
} 


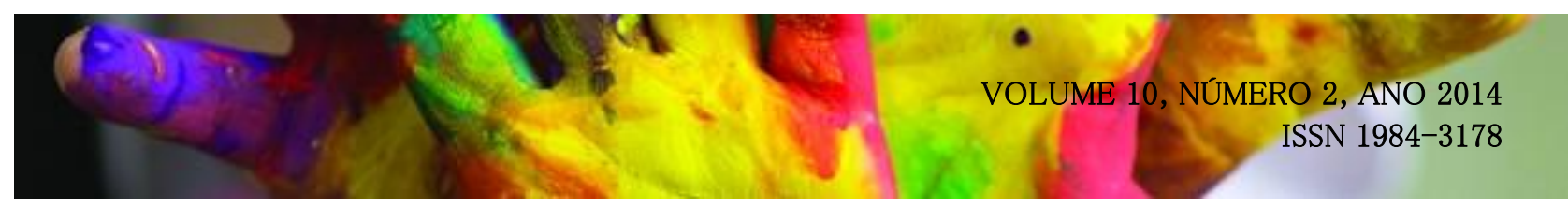

de $5^{\mathrm{a}}$ justa ${ }^{15}$. Também, confundia agudo com grave, som curto com longo e não conseguia perceber pausas curtas nos ditados rítmicos. Apresentava igualmente dificuldade na coordenação motora em exercícios de rítmica e em alguns conceitos teóricos como cadências ${ }^{16}$, por exemplo, bem como, no armazenamento ou recrutamento da informação que acabara de ouvir do professor.

O período letivo nessa escola é dividido por semestres e cada um deles, é nomeado por níveis. O curso básico dura 6 meses e se destina a preparar os alunos para entrarem no curso livre. O curso livre possui 6 níveis ( 3 anos) e o profissionalizante 4 níveis ( 2 anos).

Joana entrou na escola em 2009 no Nível Básico para ter um conhecimento geral das disciplinas. Quando passou para o Nível I, apresentou dificuldade em percepção musical e rítmica, porém, fez exame de recuperação da disciplina e foi aprovada para o Nível II, iniciando junto à prática do instrumento piando erudito. Nas aulas de piano apresentava extrema dificuldade em marcar corretamente a pulsação ${ }^{17}$ das músicas, bem como em ler as partituras propostas pela professora. Mesmo com tais dificuldades, foi aprovada para no Nível III, devido seu esforço. Quando chegou no Nível IV, suas dúvidas e dificuldades aumentaram sensivelmente e acabou refazendo três vezes esse nível, por reprovar sempre na mesma disciplina: rítmica.

Joana sempre foi uma aluna extremamente esforçada, fazia todos os deveres de casa, dificilmente faltava nas aulas e estava sempre estudando com os amigos, o que fez os professores perceberem que o motivo de sua falta de apreensão musical não era má vontade, falta de estudo ou preguiça.

Nesta escola há um programa de apoio a pessoas que possuem dificuldade de aprendizagem musical ou deficiências, coordenado por duas professoras. Devido as constantes notas baixas e reprovações Joana foi encaminhada para esse setor em 2013. Na entrevista inicial desse programa foi perguntado a Joana sobre seu histórico escolar, sendo observado que no período escolar (em sua

15 Grau conjunto que dizer notas na sequência (por ex: dó-ré) $5^{\mathrm{a}}$ justa é um tipo de intervalo em música, ou seja, a distância entre 5 notas (por ex: dó-sol).

16 Conjunto de acordes que possuem uma estrutura funcional específica dentro da música.

17 O tempo da música. 


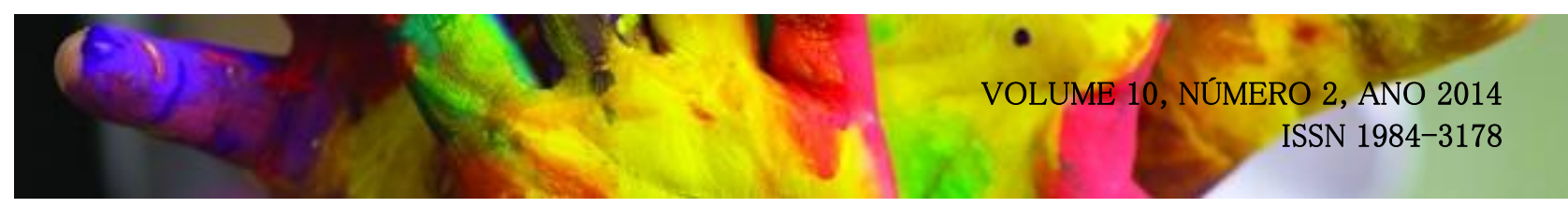

infância) ela apresentou dificuldades também na alfabetização, como troca de letras e palavras dentro de uma frase, bem como, em matemática. Foi então que uma das professoras responsáveis do programa perguntou à aluna com que mão ela escrevia e Joana comentou que era destra, mas que na primeira infância sua tendência era ser canhota, o que foi podado pela escola e família.

Desconfiada que o problema de lateralização, gerado por essa invasão alheia, pudesse ter gerado um problema mais grave de processamento auditivo, a professora solicitou que Joana fizesse o exame de Processamento Auditivo Central em um fonoaudiólogo parceiro da instituição.

O exame deu resultado de Distúrbio do Processamento Auditivo Central (DPAC) e Joana apresentou diminuição da capacidade na interação binaural, resgate ordenado de informações previamente armazenadas e nomeação dos padrões de frequência. ${ }^{18} \mathrm{Em}$ seu exame, sua lateralização está preenchida como ambidestria, o que confirmou a desconfiança da professora do programa de música.

A partir dessa comprovação, Joana começou a fazer terapia de cabine em fono para tentar diminuir essas dificuldades. Fez no total 12 seções e após isso, refez o exame que deu um resultado diferente do primeiro, com melhora na maioria das questões.

Além disso, o programa de apoio da escola de música começou a atuar para que as dificuldades pedagógicas da aluna fossem diminuídas. O primeiro passo foi avisar todos os professores que davam aulas para ela sobre seu diagnóstico e orientá-los em como proceder nas aulas e provas. A aluna precisava de mais tempo para realizar as provas, sentar mais próximo ao professor para compreendê-lo melhor e de mais repetições dos exercícios, além de comandas curtas e objetivas para que pudesse organizar a informação auditiva e torná-la em uma ação coerente.

Junto a isso, Joana começou a frequentar os grupos de rítmica e percepção da escola, oferecidos pelo programa de apoio e passou a ter currículo adaptado, isto é, nas disciplinas em que ia bem, ela dava continuidade no semestre seguinte, mas nas que tinha dificuldade, refazia ${ }^{19}$.

18 Informações retiradas do exame de processamento auditivo central realizado dia 16-05-2013.

19 A escola não conta com sistema de dependência de disciplinas. Se um aluno reprova em duas disciplinas, precisa 


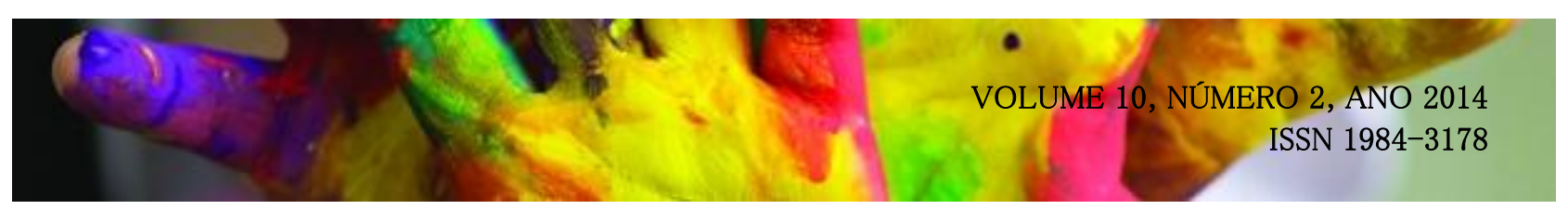

Atualmente, Joana se desenvolve musicalmente dentro do esperado para a média da escola e apesar de ainda apresentar algumas dificuldades, essas diminuíram sensivelmente, o que fez com que sua auto-estima se elevasse e com que ela passasse a acreditar mais que é capaz de aprender, pois antes, chegava a questionar se "levava jeito" para a música, pois sentia que não evoluía em relação a aprendizagem.

\title{
Discussão final
}

A questão do processamento auditivo central precisa de mais atenção no cenário musical, pois uma dificuldade pontual nessa habilidade neurológica pode comprometer sensivelmente ou mesmo, impedir o aprendizado musical.

Quando se pensa em inclusão, geralmente nos remetemos a alunos com deficiências, tais como autismo, deficiência intelectual, física, auditiva, visual e mesmo altas habilidades (VITALIANO, 2010). Pouco se fala sobre alunos com questões diferenciadas de aprendizagem, mas que não possuem laudos ou definições da origem de suas dificuldades.

Muitos problemas de aprendizagem são advindos de questões sócio-culturais ou mesmo emocionais. O homem é um ser integral, ou seja, as questões cognitivas, emocionais e o corpo estão intrinsecamente relacionados entre si e em diálogo constante com o ambiente (LOURO, 2012). Sendo assim, alguma falha no desenvolvimento da pessoa, seja neurológico, emocional ou físico, pode gerar falhas na aprendizagem, inclusive na musical. Louro (2012, p. 75) coloca:

\begin{abstract}
A aprendizagem musical é aparentemente simples, mas se observada do ponto de vista neurológico, ela apresenta alto grau de complexidade. Certas estruturas, relacionadas ao desenvolvimento global de uma pessoa, precisam ser devidamente estimuladas, caso contrário tal pessoa enfrentará grandes dificuldades em seu processo de ganho cognitivo (LOURO 2012, p. 75).
\end{abstract}

Sendo assim, o processo de inclusão precisa ser repensado e ampliado para outros contextos,

refazer o semestre em todas as quarto disciplinas que ele cursa. Mas, para alunos atendidos pelo Programa de Apoio, ações como essas são liberadas, desde que seja comprovado que o aluno em questão necessite de tais adaptações. 


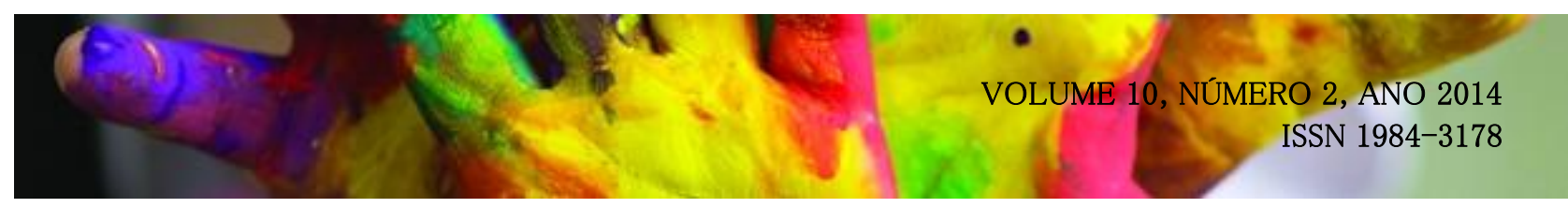

que não sejam somente da deficiência ou altas habilidades. Como coloca Vitaliano (2010, p. 24): "a educação inclusiva é o caminhar para uma escola aberta à diferença, onde todos possam fazer o seu percurso de aprendizagem independentemente das desvantagens de natureza biológica, sociocultural, psicológica e educacional. A Declaração de Salamanca, vem ao encontro disso, ao assegurar o direito de todos a educação, independente de suas diferenças, sejam elas quais forem, além de dificuldades individuais (UNESCO \& MEC-Espanha, 1994).

No caso relatado neste artigo, Joana é uma moça sem nenhuma deficiência aparente: se expressa muito bem, é interessada, independente, alfabetizada, trabalha e paga a escola com o esforço de sua profissão e não apresenta nenhuma dificuldade em compreender e se relacionar com o ambiente ao seu redor. No entanto, não conseguia aprender música, o grande foco de seu interesse pessoal.

Por muitos anos, por alguns professores, foi considerada uma aluna preguiçosa ou sem interesse. Se não fosse a investigação feita pelo programa de inclusão da escola, provavelmente Joana teria desistido por se achar incapaz de aprender, sendo que existia uma causa neurológica, invisível no contexto de sua vida diária, mas que dificultava o acesso ao mundo musical. Esse problema, que assola muitas pessoas é o Distúrbio do Processamento Auditivo Central.

Eugênio (2012, p. 993) coloca: " a compreensão adequada do som depende da integridade do sistema auditivo como um todo e o seu aprimoramento está relacionado, principalmente, a questões ambientais". Isso fica muito claro no caso de Joana, que provavelmente desenvolveu Distúrbio do Processamento Auditivo Central por conta do ambiente, ou seja, em sua época de alfabetização, a escola a obrigou a escrever com a mão direita, sendo que sua dominância lateral natural seria a esquerda.

Mas, o que teria a ver o processamento auditivo com a lateralização? A lateralização é um aspecto neurológico natural de todo ser humano. Uma pessoa é destra ou canhota. Se isso não ocorre, a pessoa pode ter problemas sérios em aspectos da cognição, tal como memória, atenção, 


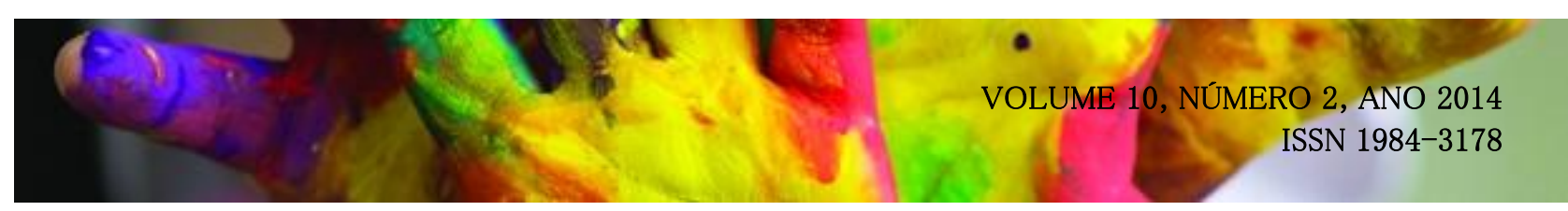

organização do pensamento, abstração, além de problemas de coordenação motora e dificuldade no processamento visual e auditivo, como afirma Louro (2012, p. 93-95):

A dominância lateral significa que já houve a definição de um hemisfério cerebral. Tal definição é a base neurológica para toda a maturação cortical [...] Quem apresenta ambidestria ou lateralização não-definida provavelmente enfrentará dificuldades associadas, principalmente em atividades que requeiram movimentos ou pensamentos estreitamente definidos [...] Para um bom desenvolvimento é necessário dominância lateral de mão, de perna, de ouvido e de olho (LOURO, 2012, p. 93-95).

Imagine uma sala de aula na qual a professora está falando e, ao longe, há crianças brincando no pátio. Para se entender o que o professor está dizendo é necessário a atenção seletiva no foco principal (professor). Uma criança com problemas de processamento auditivo, terá, possivelmente, dificuldade na questão figura-fundo, ou seja, não conseguirá isolar o som principal (professor falando) do resto do ambiente. Conseguir se concentrar no foco auditivo principal depende de uma boa maturação neurológica, que está intimamente relacionada com a lateralização (LOURO, 2012).

Joana foi obrigada a escrever com a mão direita, quando sua natureza pedia o contrário. Isso gerou uma lateralização confusa, o que levou a problemas na alfabetização, tais como: trocas de letras, dificuldade com números e problemas de memória. $\mathrm{Na}$ época da escola, esses problemas foram aparentemente sanados pelo estudo intensivo por parte de Joana, que precisava se esforçar muito mais que os demais para conquistar a aprendiagem, até mesmo de conteúdos simples. Mas, diante da aprendizagem musical, essa questão se potencializou e ela não conseguiu mais resolver a questão somente estudando muito.

Eugênio (2012, p. 997) coloca que as habilidades cognitivas envolvidas na aprendizagem musical, estão relacionadas à questão fonológica e aprimoramento do processamento auditivo. Como Joana apresentou dificuldade na época da alfabetização, devido a uma lateralização confusa, a aprendizagem musical ficou comprometida pelas questões relacionadas ao processamento auditivo. O estudo musical estimula o desenvolvimento da percepção auditiva e o treino musical pode agir como facilitador para o desenvolvimento fonológico e para as habilidades do processamento auditivo (EUGÊNIO, 2012). No entanto, no caso de Joana, por ela começar a 


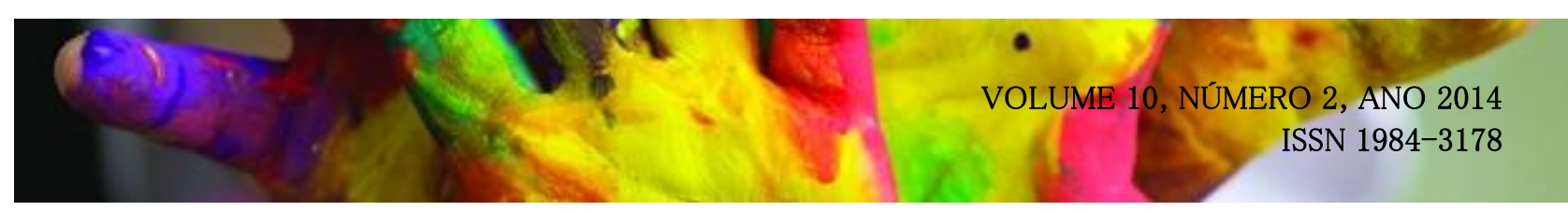

estudar música já adulta, essa realidade não se afirmou, pois em seu caso, o distúrbio já estava instalado há muito tempo.

Como já dito, a aluna apresentou dificuldade em interação binaural, resgate ordenado de informações previamente armazenadas e nomeação dos padrões de frequência. Isso significa que seu cérebro não era capaz de fazer com facilidade e rapidez a comunicação entre os hemisférios, no que tange o som (integração binaural). Além disso, possuía dificuldade em resgatar informações auditivas memorizadas e não conseguia nomear alturas, ou seja, sons graves, médios e agudos. Isso tudo gerou os impedimentos musicais já relatados, pois sem memória, sem organização neurológica e sem capacidade de nomear as alturas, fica quase inviável realizar um ditado melódico e rítmico.

Por isso, a importância de um trabalho direcionado de fonoaudiologia nessa situação. Como é possível se observar pelo relato de caso, a aluna apresentou dificuldade em aspectos neurológicos, e devido a essa questão, não seria possível esperar ou exigir que o problema fosse sanado somente por estratégias pedagógicas. A intervenção pedagógica é fundamental para a permanência de alunos com dificuldade na escola e para contribuir com o aprendizado. Mas, somente profissionais da saúde podem resolver as questões neurológicas, físicas ou emocionais dos alunos. Sendo assim, é fundamental um trabalho em equipe quando diante de casos complexos como o de Joana (LOURO, 2012).

Então, é importante que os professores, inclusive de música, tenham uma formação adequada no que tange ao conhecimento de aspectos relacionados ao desenvolvimento neuropsicomotor e processamento auditivo, para que possam diferenciar dificuldades em relação ao aprendizado de falta de estudo, como também, para saberem direcionar o melhor tipo de atendimento para cada caso.

Quando a questão é uma deficiência perceptível, ninguém questiona a necessidade de recursos alternativos, materiais, conteúdos e provas diferenciadas. Mas, quando a pessoa aparentemente não apresenta nenhuma deficiência, mas mesmo assim, não consegue aprender com facilidade, ela é às vezes vista como preguiçosa, não estudiosa ou no caso da música, como não portadora de talento e potencial musical. 


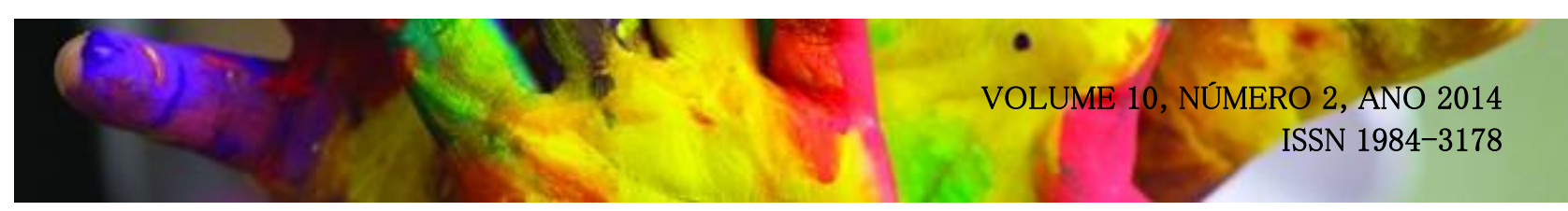

Soares (2009, p. 107) reitera a afirmação acima, dizendo que é comum no meio musical ainda acharem que o "dom ou talento" são coisas inatas e que pessoas que não aprendem com facilidade, não podem ter acesso a música. Esse tipo de pensamento é extremamente excludente e dificulta o acesso à aprendizagem musical por parte de pessoas que apresentam dificuldade, sendo que, muitas vezes essa dificuldade que é vista como falta de talento, pode, na verdade, ser um déficit no aprendizado ou um problema de Processamento Auditivo Central.

Louro e Andrade (2009, p. 128) colocam que:

\begin{abstract}
A música é uma possibilidade que se apresenta a todos, sendo assim, não cabe a nós julgarmos quem pode ou deve de quem não pode ou não deve estudá-la. O que precisamos é estar preparados para receber a diversidade. [...] O professor no contexto da aprendizagem deve buscar objetivos claros na sua prática, tendo um planejamento pautado na realidade de seu aluno (LOURO \& ANDRADE, 2009, p. 128).
\end{abstract}

Perrenoud (2002, p. 12) comenta sobre a importância do professor em se envolver num compromisso crítico no debate social sobre a finalidade da escola e seu papel na sociedade, em vistas a aprender a trabalhar cooperativamente na escola e dialogar com família e comunidade. Sendo assim, ele chama a atenção para um item fundamental, sem o qual, a inclusão fica espinhosa demais: o trabalho em equipe.

Quando se fala em inclusão, dialogamos diretamente com a necessidade de um trabalho baseado numa rede de apoio de diversos profissionais e às vezes, de instituições. No caso de Joana, se a escola não oferecesse o serviço de apoio à inclusão, talvez sua dificuldade teria a levado a desistir. Foi a investigação feita pelos profissionais desse programa, a partir de questionamentos e percepções pedagógicas, junto com a intervenção de um fonoaudiólogo de outra instituição, que fez com que fosse descoberto e tratado o Distúrbio do Processamento Central em tal aluna. Isso fez total diferença em seu processo de aprendizado e no sucesso das intervenções posteriores.

Foram necessárias intervenções pedagógicas, tais como provas com tempo ampliado, adaptação de currículo e disciplinas, além de aulas de apoio extra curricular para que a aluna começasse a progredir, mostrando mais uma vez a necessidade do trabalho em equipe. Isso mais uma vez mostra 


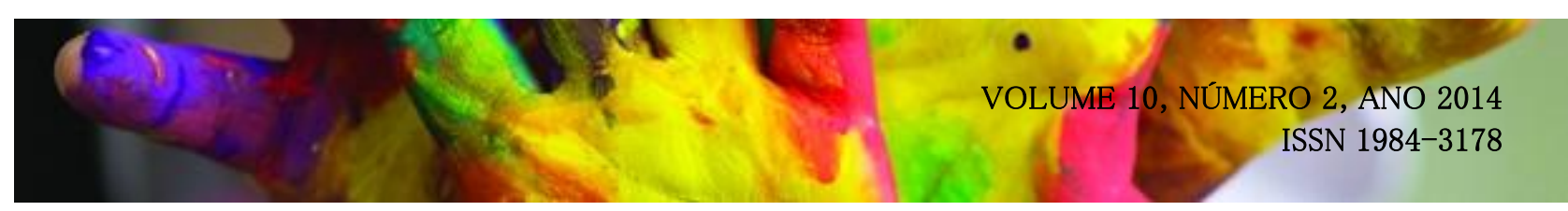

que o dito popular "a união faz a força" é vero. Sendo assim, para que se ocorra uma inclusão adequada, faz-se necessário repensarmos o sistema de ensino, a formação do professor de música, os recursos de intervenções pedagógicas e as representações sociais sobre o aluno ideal versus o real, talento musical versus dificuldade, dentre outras questões.

Para completar, Louro e Andrade (2009, p. 129) afirmam:

Temos que acreditar em nossos alunos, sejam eles como forem; acreditar em nosso potencial como profissional; acreditar que a força de vontade, além de uma educação bem direcionada e muito treino, pode fazer com que as pessoas aparentemente sem possibilidades superem suas limitações e alcancem resultados musicais de qualidade.

Acreditar que é possível uma educação musical mais humanizada, que não [...] busque somente resultados performáticos, mas que antes veja a música como uma ferramenta fundamental para acionar o processo de autoconhecimento e crescimento interior, bem como, uma maneira de expressão e aprendizado essencial para a vida de TODAS as pessoas (LOURO \& ANDRADE, 2009, p. 129).

Enfim, é fundamental resignificarmos o papel social da escola e entender que seu objetivo não é somente oferecer conteúdos aos alunos, mas também ajudá-los a crescer em todos os sentidos e ampará-los em suas dificuldades. Além disso, é crucial termos professores de música mais preparados, com conhecimentos específicos sobre problemas de aprendizagem, desenvolvimento cognitivo, processamento auditivo, inclusão, dentre outros assuntos, para que os alunos não sejam julgados como preguiçosos ou incapazes diante de dificuldades reais, que muitas vezes podem ser sanadas através de intervenções pontuais. Por último, é necessário acreditarmos que todos podem aprender e que através da afetividade e direcionamento pedagógico e médico consciente, podemos promover a inclusão e alcançar objetivos significativos. Nas palavras da própria Joana ${ }^{20}$ :

Hoje vejo o resultado gradativo dia após dia, tenho uma leitura fluente em rítmica e consigo escrever os ditados sabendo qual o real valor da figuras, algo que antes do tratamento eu não conseguia fazer. Na percepção musical houve uma grande melhora nas leituras e ditados. Hoje nas aulas de piano estou atingindo as metas que um dia pensei que nunca alcançaria. De todo o meu relato o que realmente fez a diferença foi a ajuda e a orientação das professoras envolvidas, sei que parte do aprendizado depende de mim, mas sem elas seria impossível chegar onde estou. Me sinto bem hoje, e não tenho medo de dizer "NÃO SEI" ou "NÃO ENTENDI", pois sei que tenho pessoas que tem muito carinho em me ajudar no meu aprendizado. 


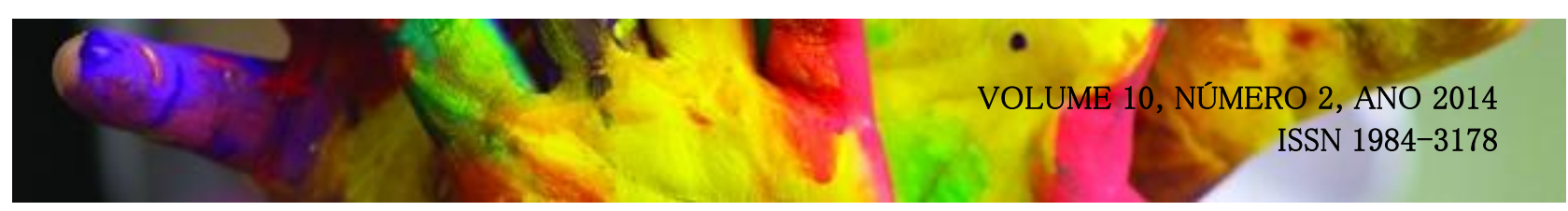

\section{REFERÊNCIAS}

ALVAREZ, A.M.; RAMOS, B.D.; SANCHEZ, M.L. Neuroaudiologia e processamento auditivo: novos paradigmas. RBM Revista Brasileira de Medicina. Rio de Janeiro, v.2, p.51-58, 2007.

CIOQUETA, E. Efeito da prática musical no processamento auditivo em escolares de sete a quatorze anos de idade. Dissertação de mestrado. Universidade Federal de Santa Maria: Centro de ciências da saúde. Pós-graduação em distúrbios da comunicação humana. Santa Maria: UFSM, 2006.

CUERVO, L. Articulações entre Música, Educação e Neurociências: ideias para o ensino superior. In VII SIMCAM -Simpósio de Cognição e Artes Musicais, 7., 2011. Brasília. Anais do VII SIMCAM. Brasília: UNB, p. 20-25.

DESSEN, M.A.; BRITO, A.M.W. Reflexões sobre a deficiência auditiva e o atendimento institucional de crianças no Brasil. Paideia. Ribeirão Preito, No. 12-13 fev/ago. 1997.

EUGÊNIO, M. et al. Desenvolvimento cognitivo, auditivo e linguístico em crianças expostas à música: produção de conhecimento nacional e internacional. Revista CEFAC, vol. 14, n.5, p. 9921003. Setembro e Outubro de 2012.

FROTA, S.; PEREIRA, L., D. Processamento auditivo: estudo em crianças com distúrbio da leitura e da escrita. Rev. Psicopedagogia, vol. 27, n.83, p. 214-22, São Paulo, 2010.

GARCIA, V.L.; PEREIRA, L.D.; FUKUDA, Y. Atenção seletiva: PSI em crianças com distúrbio de aprendizagem. Revista Brasileira de Otorrinolaringologia, p.404-411, mai/jun. 2007.

GODOY, S. Concepções teóricas acerca das funções executivas e das altas habilidades. Caderno de pós-graduação em Distúrbios do desenvolvimento. vol. 10, n.1, p. 76-85, São Paulo, 2010.

HUIZINGA, M., et al. Age-related inexecutive function: developmental trends and a latent variable analysis. Rev. Neuropsychologia, vol. 44, p. 2017-2036, 2006.

JACOB, L.C.B.; ALVARENGA, K.F.; ZEIGELBOIM, B.S. Avaliação audiológica do sistema nervoso auditivo central. International archives of otorhinolaryngology. Vol.4 No.4 Out/dez. 2000.

KOZLOWSKI, L., et al. A efetividade do treinamento auditivo na desordem do processamento auditivo central: estudo de caso. Revista Brasileira de Otorrinolaringologia, p.427-432, mai./jun 2004.

LIMA, S. Percepção, processamento e treinamento auditivo musical com usuários de implante 


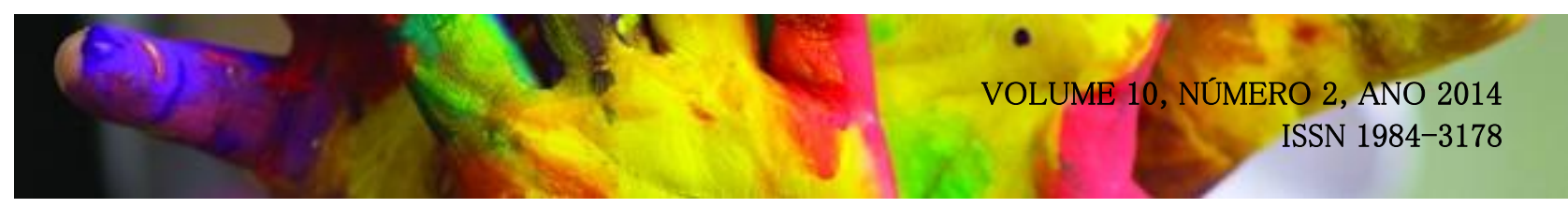

coclear. Dissertação de Mestrado. Pós-graduação em música. Universidade Federal de Minas Gerais. Minas Gerais: UFMG, 2010.

LIPORACI, F.D. Estudo do processamento auditivo temporal(resolução e ordenação) em idosos. Dissertação de Mestrado. Universidade Veiga de Almeida. Rio de Janeiro: UVA, 2009.

LENT, R. Cem bilhões de neurônios?: conceitos fundamentais de neurociências. $2^{\text {a }}$ Edição. São Paulo: Editora Atheneu, 2010.

LOURO, V.; ANDRADE, A. Música e inclusão: uma reflexão a partir da psicomotricidade e plasticidade cerebral. IN: DALL'ACQUA, Maria. ZANIOLO, Leandro. Educação Inclusiva e Perspectiva: reflexões para a formação de professores. $1^{a}$ edição. Curitiba: Editora CRV, 2009.

LOURO, V. Fundamentos da aprendizagem musical da pessoa com deficiência. São Paulo: Editora Som, 2012.

MARTINS J.S., PINHEIRO M., BLASI, H.F. A utilização de um Software infantil na terapia fonoaudiológica de distúrbio do processamento auditivo central. Revista Sociedade Brasileira de Fonoaudiologia, p. 398-404,2008.

MENDONÇA, J. LEMOS, S. Relação entre prática musical, processamento auditivo e apreciação musical em crianças de 5 anos. Revista da ABEM, vol. 23, p.58-66. Porto Alegre, Março de 2010.

MÜLLER, R., F. Considerações sobre percepção auditiva e processos de ensino-aprendizagem na educação musical infantil. In XI Jornada do HISTEDBR, 11. Cascavel. Anais da XI Jornada do HISTEDBR, Cascavel, 2013.

MUSZKAT, M.; CORREIA, C., M. F.; CAMPOS, S., M. Música e Neurociências. Rev. Neurociências vol.8, n.2, p. 70-75, 2000.

NISHIHATA, M. et al. Processamento temporal, localização e fechamento auditivo em portadores de perda auditiva unilateral. Rev. Soc. Bras. Fonoaudiol. vol.17, n.3, p.266-73, 2012.

NUNES, C. L.; PEREIRA, L.; CARVALHO, G. S; Contribuição da avaliação do processamento auditivo na investigação das dificuldades de aprendizagem. In $12^{\circ}$ Colóquio de Psicologia e Educação ISPA, 12., 2012. Actas do $\mathbf{1 2}^{\circ}$ Colóquio de Psicologia e Educação ISPA, p. 681-694.

PACHECO, E. Audição e equilíbrio. Retirado de : <

http://www.ebah.com.br/content/ABAAAAZPsAE/audicao-equilibrio > Acesso em 13 de Outubro de 2014.

PAULUCCI, B.P. Fisiologia da audição. Retirado

de :<http://www.otorrinousp.org.br/imageBank/seminarios/seminario_28.pdf > Acesso em 14 out. 2014. 


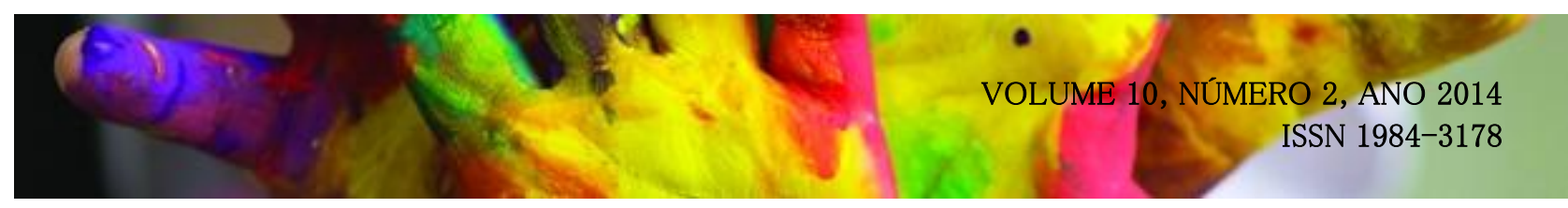

PEREIRA, L. V manual de otorrinolaringologia pediátrica da IAPO, Avaliação dos distúrbios do processamento auditivo em pré-escolares. Guarulhos- SP: Lis Gráfica e Editora Ltda, 2006.

PERRENOUD, P. A prática reflexiva no ofício do professor: profissionalização e razão pedagógica. Porto Alegre: Artmed, 2002.

PARRA, V.M. et al. Testes de padrão de frequência e de duração em idosos com sensibilidade auditiva normal. Revista Brasileira de Otorrinolaringologia, P.517-523, jul/ago. 2004.

PRANDO, M. L. et al. Relação entre habilidades de processamento auditivo e funções neuropsicológicas em adolescentes. Rev. CEFAC. vol.12, n.4, p. 646-661, 2010.

RIBAS, A.; ROSA, M.R.D.; KLAGENBERG, K. Avaliação do processamento auditivo em crianças com dificuldades de aprendizagem. Revista psicopedagogia, P.2-8, 2007.

ROCHA, V. C.; BOGGiO, P.; A música por uma óptica neurocientífica. Rev. Per Musi. Belo Horizonte, n.27, p.132-140, 2013.

SAMELLI, A.G.; SCHOCHAT, E. Processamento auditivo, resolução temporal e teste de detecção de GAP: Revisão da literatura. Revista CEFAC Vol.10, 2008.

SLOBODA, J. The Musical Mind: The Cognitive Psychology of Music. Reed. com correções. Oxford: Clarendon Press, 1989.

SHINN, J.B. Temporal processing: the basic. The Hearing Journal, p.52. Junho 2003.

STEINER, L. Processamento auditivo central. Monografia de conclusão de curso. Centro de especialização em fonoaudiologia clínica. Especialização em audiologia clínica: CEFAC, 1999.

SOARES, L. O professor de música e a educação inclusiva. IN: DALL ACQUA, Maria. ZANIOLO, Leandro. Educação Inclusiva e Perspectiva: reflexões para a formação de professores. $1^{a}$ edição. Curitiba: Editora CRV, 2009.

UNESCO \& MEC-Espanha. Declaração de Salamanca e Linha de Ação Sobre Necessidades Educacionais Especiais. Brasília: CORDE, 1994.

VITALIANO, R. Formação de professores para inclusão de alunos com necessidades educacionais especiais. Londrina: EDUEL, 2010.

ZALCMAN, T.M.; SCHOCHAT, E. A eficácia do treinamento auditivo formal em indivíduos com transtorno de processamento auditivo. Revista brasileira de Fonoaudiologia, P.310-314, 2007. 